\title{
Type II congenital pulmonary airway malformation in an esophageal lung
}

\author{
Blanca Estela Martínez-Martínez MD¹, María Elena Yuriko Furuya MD PhD², Irma Martínez-Muñiz MD², \\ Mario $\mathrm{H}$ Vargas MD MSc${ }^{2}$, Rosalinda Flores-Salgado $\mathrm{MD}^{4}$
}

\begin{abstract}
BE Martínez-Martínez, MEY Furuya, I Martínez-Muñiz, MH Vargas, R Flores-Salgado. Type II congenital pulmonary airway malformation in an esophageal lung. Can Respir J 2013;20(3):e52-e54.
\end{abstract}

A seven-month-old girl, born prematurely (birth weight $1000 \mathrm{~g}$ ) from a twin pregnancy, was admitted to hospital due to recurrent pneumonia and atelectasis. She experienced cough and respiratory distress during feeding. The right hemithorax was smaller than the left, with diminished breath sounds and dullness. Chest $\mathrm{x}$-rays revealed decreased lung volume and multiple radiolucent images in the right lung, as well as overdistention of the left lung. An esophagogram revealed three bronchial branches arising from the lower one-third of the esophagus, corresponding to the right lung and ending in a cul-de-sac. A diagnosis of esophageal lung was established. On bronchography, the right lung was absent and the trachea only continued into the left main bronchus. Echocardiography and angiotomography revealed agenesis of the pulmonary artery right branch. The surgical finding was an esophageal right lung, which was removed; the histopathological diagnosis was type II congenital pulmonary airway malformation in an esophageal lung.

Key Words: Bronchopulmonary malformation; Chronic aspiration; Congenital cystic adenomatoid malformation; Congenital pulmonary airway malformation; Esophageal lung; Recurrent pneumonia

Learning objectives:

- To recognize clinical and radiological data suggestive of an esophageal lung, and to consider this condition in the differential diagnosis of persistent or recurrent pneumonia.

- To be aware that two lung malformations may occur simultaneously in the same patient.

CanMEDS competency: Medical Expert

Pre-test

- What clinical and radiological data lead to suspicion of an esophageal lung?

- What are the pathognomonic features of an esophageal lung in the barium swallow?

$\mathrm{T}$ he esophageal lung or esophageal bronchus is characterized by an aberrant bronchus or lung that arises from the esophagus, with total absence of ventilatory function in the involved pulmonary tissue (1-5). The present report describes an unusual case of a type II congenital pulmonary airway malformation (CPAM) that occurred in an esophageal lung (6).

\section{CASE PRESENTATION}

The patient was a seven-month-old girl born after 34 weeks' gestation in a twin pregnancy, with a birth weight of $1000 \mathrm{~g}$. In the neonatal

\section{Une malformation congénitale des voies aériennes pulmonaires de type II dans un poumon œsophagien}

Une fillette de sept mois née prématurément (poids de $1000 \mathrm{~g}$ à la naissance) après une grossesse gémellaire a été hospitalisée en raison de pneumonies récurrentes et d'atélectasie. Elle toussait et présentait une détresse respiratoire lors des repas. L'hémithorax droit était plus petit que le gauche, le murmure vésiculaire était réduit et le son, sourd. Les radiographies pulmonaires ont révélé une diminution du volume pulmonaire et de multiples images perméables aux rayons $\mathrm{X}$ dans le poumon droit, ainsi qu'une surdistension du poumon gauche. L'œsophagogramme a révélé trois ramifications bronchiques provenant du tiers inférieur de l'œsophage, correspondant au poumon droit et se terminant en cul-de-sac. Les chercheurs ont posé un diagnostic de poumon œsophagien. À la bronchographie, le poumon droit était absent et la trachée ne se poursuivait que dans la bronche souche gauche. L'échocardiogramme et l'angiotomographie ont révélé une agénésie de la branche de l'artère pulmonaire droite. L'opération a permis de découvrir un poumon droit œsophagien, dont on a procédé à l'ablation. Le diagnostic histopathologique en était un de malformation congénitale des voies aériennes pulmonaires sous forme de poumon œsophagien.

period, she developed pneumonia and required mechanical ventilation for 40 days, and was discharged eight days later. She was hospitalized on three more occasions due to pneumonias and was sent to the Hospital de Pediatría, Centro Médico Nacional Siglo XXI (Mexico DF) for evaluation and treatment.

On admittance, her weight was $2900 \mathrm{~g}$, oxygen saturation was $92 \%$ on room air, with respiratory distress, asymmetrical thorax due to a smaller size of the right hemithorax. She arrived without an orogastric tube and, thus, previous oral feeding was assumed, but she experienced an episode of choking after trying to initiate by oral route.

A chest radiograph revealed a pencil-like tapering of her tracheal air column, and the right lung was smaller and with multiple radiolucent images compared with the left lung, which was overdistended (Figure 1). Bronchoscopy revealed 20\% subglottic stenosis and progressive diminution of tracheal lumen and, thus, the carina could not be visualized. Endoscopy showed incompetent hiatus. In contrasted images, the barium swallow and a Valsalva manoeuvre revealed a three-branch ramification emerging from the lower one-third of the esophagus, which ended in a cul-de-sac, establishing the diagnosis of esophageal lung (Figure 2). An echocardiogram showed probable agenesis of the right pulmonary artery, neoformation of blood vessels in the esophageal lung and venous return through pulmonary veins draining to the right atrium. Angiotomography with three-dimensional reconstruction clearly showed diminution of the tracheal diameter, which continued with the left main bronchus, and the esophageal lung emerging from the esophagus (with an orogastric tube inside); the right lung had

${ }^{1}$ Departamento de Neumología; ${ }^{2}$ Unidad de Investigación Médica en Enfermedades Respiratorias; ${ }^{3}$ Departamento de Imagenología; ${ }^{4}$ Departamento de Anatomía Patológica, Hospital de Pediatría, Centro Médico Nacional Siglo XXI, Instituto Mexicano del Seguro Social, México DF, México

Correspondence: Dr Blanca Estela Martínez-Martínez, UMAE Hospital de Pediatría, CMN Siglo XXI, IMSS. Av. Cuauhtémoc 330,

Col. Doctores, CP 06720, México DF, México. Telephone 55-56276900 ext 22289 or 22290, e-mail blancaestelamartinez@prodigy.net.mx 


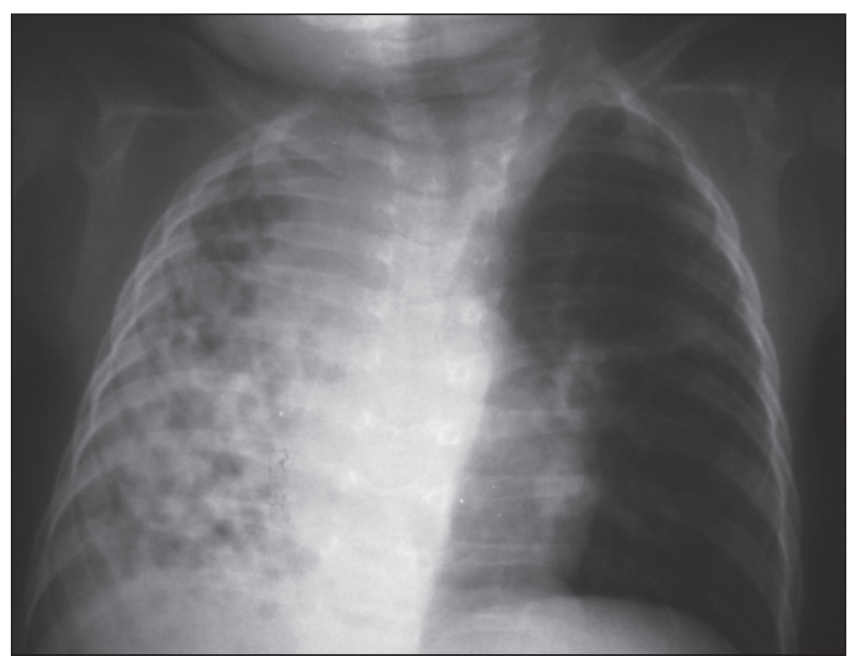

Figure 1) Chest radiograph showing dilation of the proximal trachea, with pencil-like tapering, right lung with diminished volume and multiple radiolucent images, and overdistension of the left lung

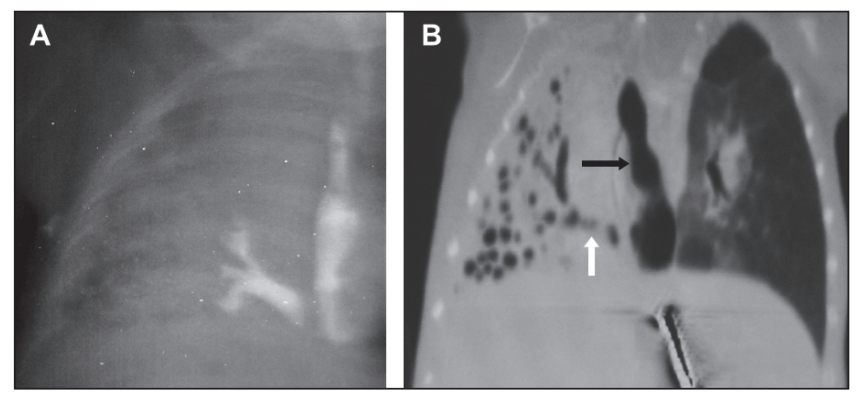

Figure 2) Images of the esophageal lung. A Esophagogram showing three branches emerging from the lower one-third of the esophagus and ending in cul-de-sac. B The coronal plane of computed tomography shows the esophagus (black arrow) and the bronchus for the esophageal lung (white arrow)

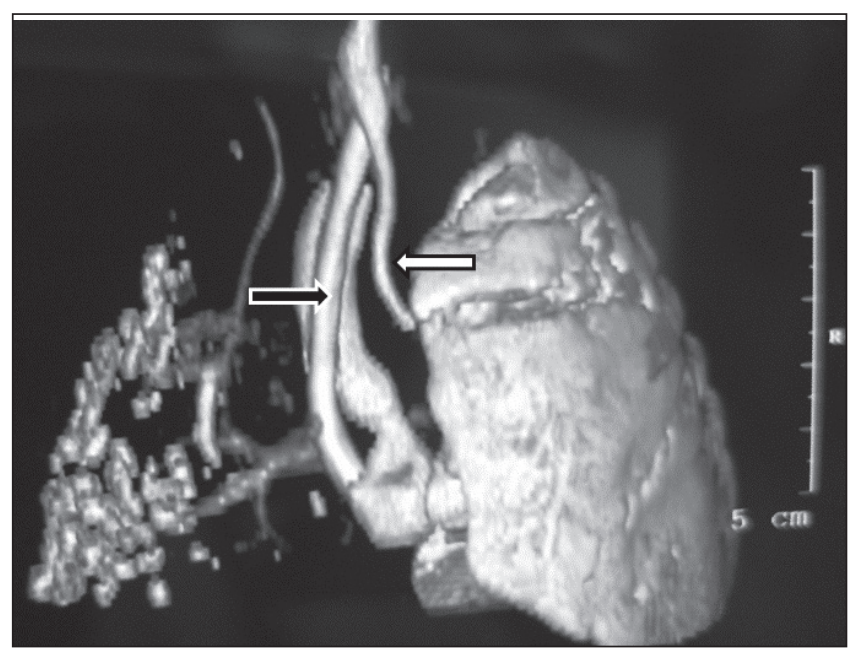

Figure 3) Computed angiotomography showing diminution of the tracheal diameter, which continues with the left main bronchus (white arrow), and the esophageal lung emerging from the esophagus (with an orogastric tube inside, black arrow); the right lung had lower volume than the left side, with distortion of the normal architecture

lower volume than the left, with distortion of the normal architecture due to hypodense lesions (Figure 3). Additionally, this imaging modality also demonstrated venous drainage of the esophageal lung into the left atrium (Figure 4). Bronchography showed that the trachea was in continuation with the left main bronchus, and the right lung was excluded (Figure 5).

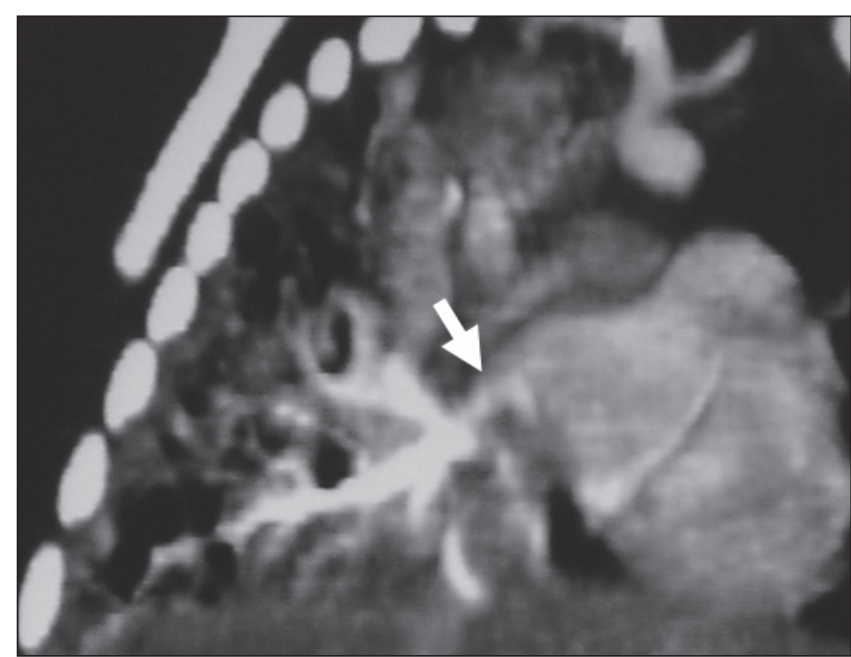

Figure 4) Computed angiotomography showing the venous drainage of the esophageal lung into left atrium (white arrow)

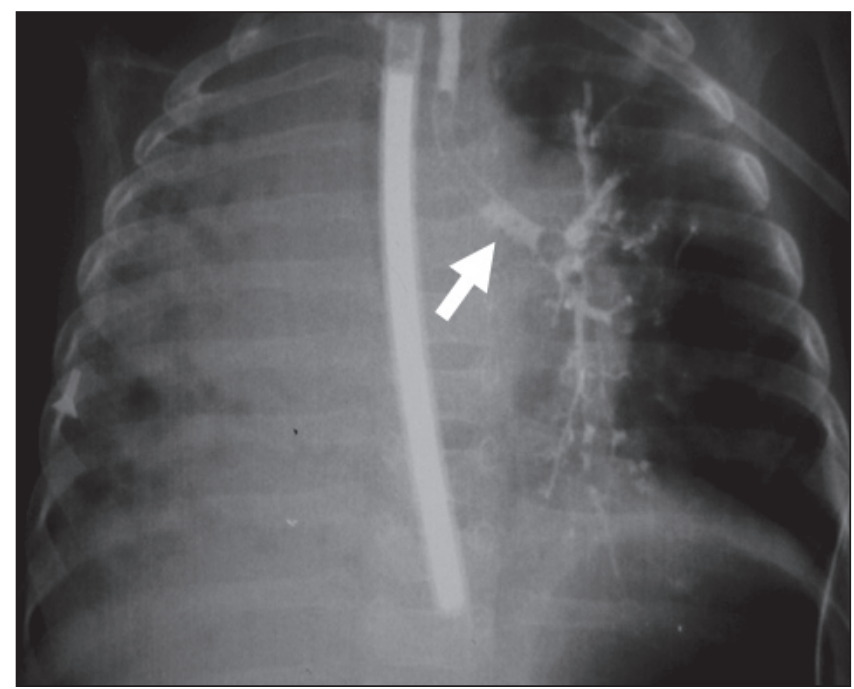

Figure 5) Bronchography revealing exclusion of the right lung. The trachea continues with the left main bronchus (white arrow), and abnormalities of the left tracheobronchial tree are present

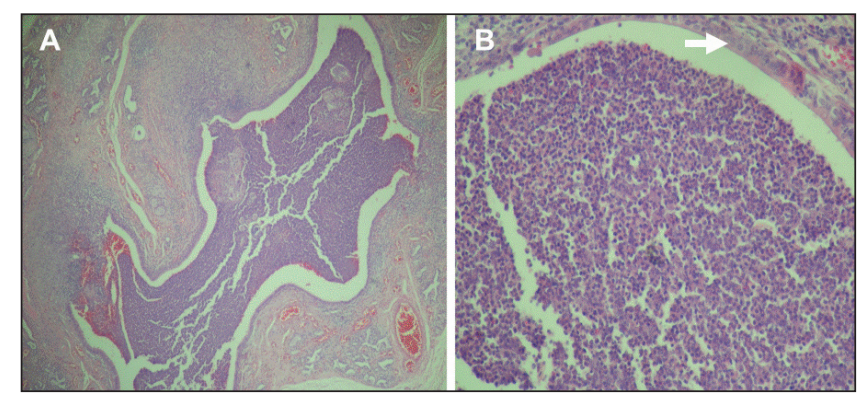

Figure 6) Histological section of the lung parenchyma. A A distorted architecture with multiple cystic spaces can be seen (original magnification $\times 10$ ). B It is apparent that these cysts are covered by pseudostratified columnar epithelium (white arrow) and contain neutrophilic exudate (original magnification $\times 40$ )

The intraoperative findings were right lung with main bronchus arising from the esogaphus, with remnant veins in its hilum and lacking systemic arterial blood supply. A right pneumonectomy was performed. The histopathological analysis reported a type II congenital cystic adenomatoid malformation (Figure 6), corresponding to type II CPAM in the current nomenclature (6). 


\section{DISCUSSION}

To our knowledge, the present case is the first report of type II CPAM occurring in an esophageal lung. In this patient, the malformation corresponded to a group II classification of bronchopulmonary malformations communicating with the foregut $(1,2,6)$.

Respiratory distress associated with feeding and persistent or recurrent episodes of pneumonia, as seen in the present case, are the most common clinical events in children with an esophageal lung. Bronchiectasis, hemoptysis, gastrointestinal hemorrhage and dysphagia can also be present (3-5). Diagnosis is made using esophagography, although other useful imaging modalities are computed tomography, magnetic resonance imaging and angiotomography. When an esophageal bronchus or esophageal lung is suspected, angiotomography shows parenchymal abnormalities and depicts venous and arterial blood flow with higher precision than other studies. Other complementary imaging modalities are fibreoptic bronchoscopy, digestive endoscopy and echocardiography. When the malformation and its vasculature cannot be delimited, arteriography is recommended (3-5).

An esophageal bronchus or esophageal lung is often unilateral. Malformed airways usually arise from the lower esophagus and the gastroesophageal junction, and histopathology shows squamous epithelium in the esophageal end of the communication and ciliated pseudostratified columnar epithelium on the pulmonary side (3).

Many malformations, such as pulmonary hypoplasia or agenesis, pulmonary sequestration, and malformations of the heart, kidneys, ribs, vertebral column and digestive tract have been associated with this entity (4). In this context, our patient presented other congenitalassociated malformation such as agenesis of the pulmonary artery right branch and congenital tracheal stenosis.

\section{REFERENCES}

1. Srikanth MS, Ford EG, Stanley P, Mahour GH. Communicating bronchopulmonary foregut malformations: Classification an embryogenesis. J Pediatr Surg 1992;27:732-6.

2. Heithoff KB, Sane SM, William HJ, Jarvis CJ, Carter J, Kane P. Bronchopulmonary foregut malformations: A unifying etiological concept. Am J Roentgenol 1976;126:46-55.

3. De la Cruz OA, Marco-Valls MT, Gil-Vázquez JM, Obiols-Arderius P, Martín-Martín C, Bosque-García M. Secuestro pulmonar extralobar con bronquio esofágico supernumerario asociado. An Esp Pediatr 2002;56:261-2.
Surgical resection of the involved lung parenchyma is curative in the majority of cases. When a normal lung is demonstrated, more conservative surgery has been suggested in which an anastomosis of the esophageal bronchus is performed on the normal tracheobronchial tree $(3-5)$.

\section{CONCLUSIONS}

An esophageal lung must be considered in children with cough or respiratory distress during feeding, recurrent pneumonia since birth or persistent opacities in chest $\mathrm{x}$-rays. Other associated malformations, including CPAM as in the present case, must be investigated.

Post-test
- What clinical and radiological data lead to suspicion of an
esophageal lung?
An esophageal lung must be suspected when respiratory distress
associated with feeding (choking) and a persistent or recurrent
pulmonary opacity in the chest x-rays are present.
- What are the pathognomonic features of an esophageal lung in
the barium swallow?
In an esophageal lung, contrasted images with barium swallow
and with Valsalva manoeuvre can reveal the branch ramification of
a rudimentary or well-formed tracheobronchial tree emerging from
the esophagus.

DISCLOSURE: The authors report no conflicts of interest with any company or organization with financial interest in the subject matter, or any other actual or potential conflicts of interest.

4. Yankovic F, Varela BP, Casado FC, Herrera GO, Latorre LJ. Pulmón esofágico: Caso clínico. Rev Chil Pediatr 2006;77:604-7.

5. Lallemand D, Quignodon JF, Courtel JV. The anomalous origin of bronchus from the esophagus: Report of three cases. Pediatr Radiol 1996;26:179-82.

6. Stocker JT. Cystic lung disease in infants and children. Fetal Pediatr Pathol 2009;28:155-84. 


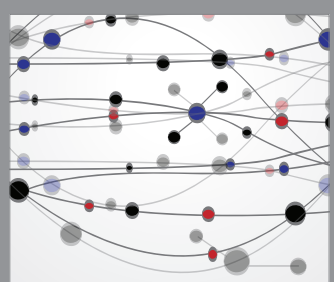

The Scientific World Journal
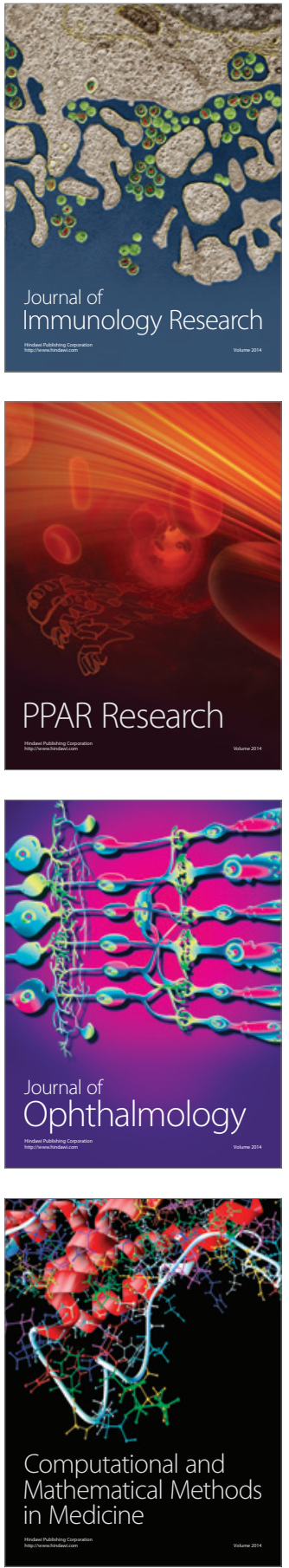

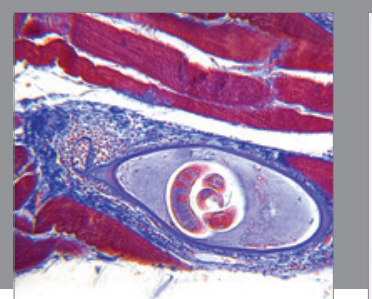

Gastroenterology Research and Practice

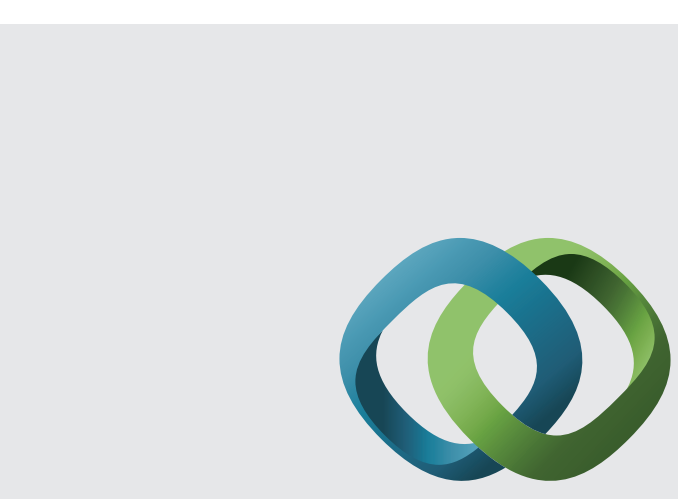

\section{Hindawi}

Submit your manuscripts at

http://www.hindawi.com
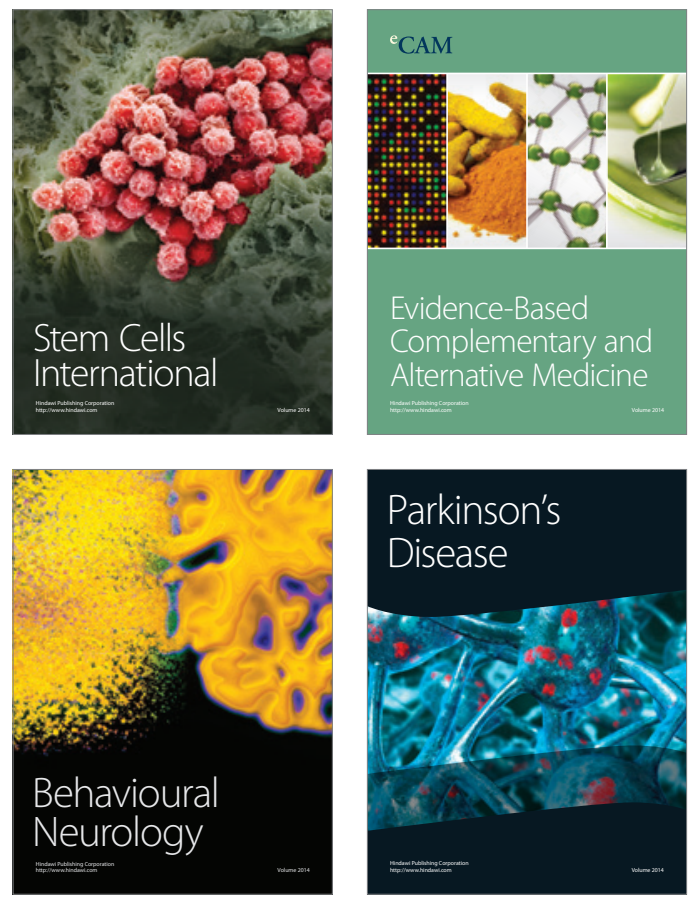
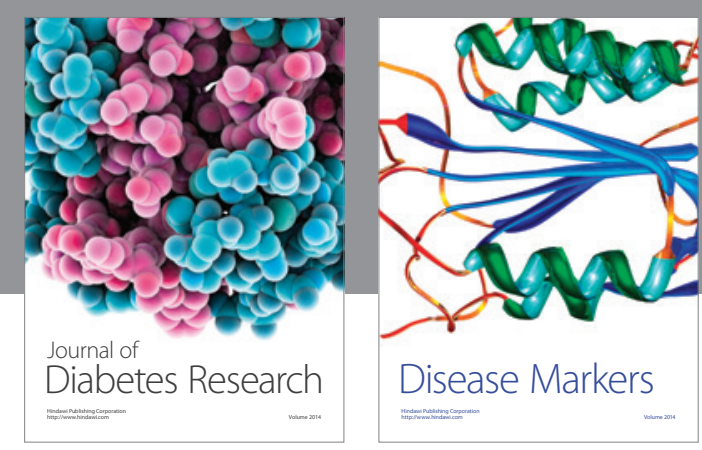

Disease Markers
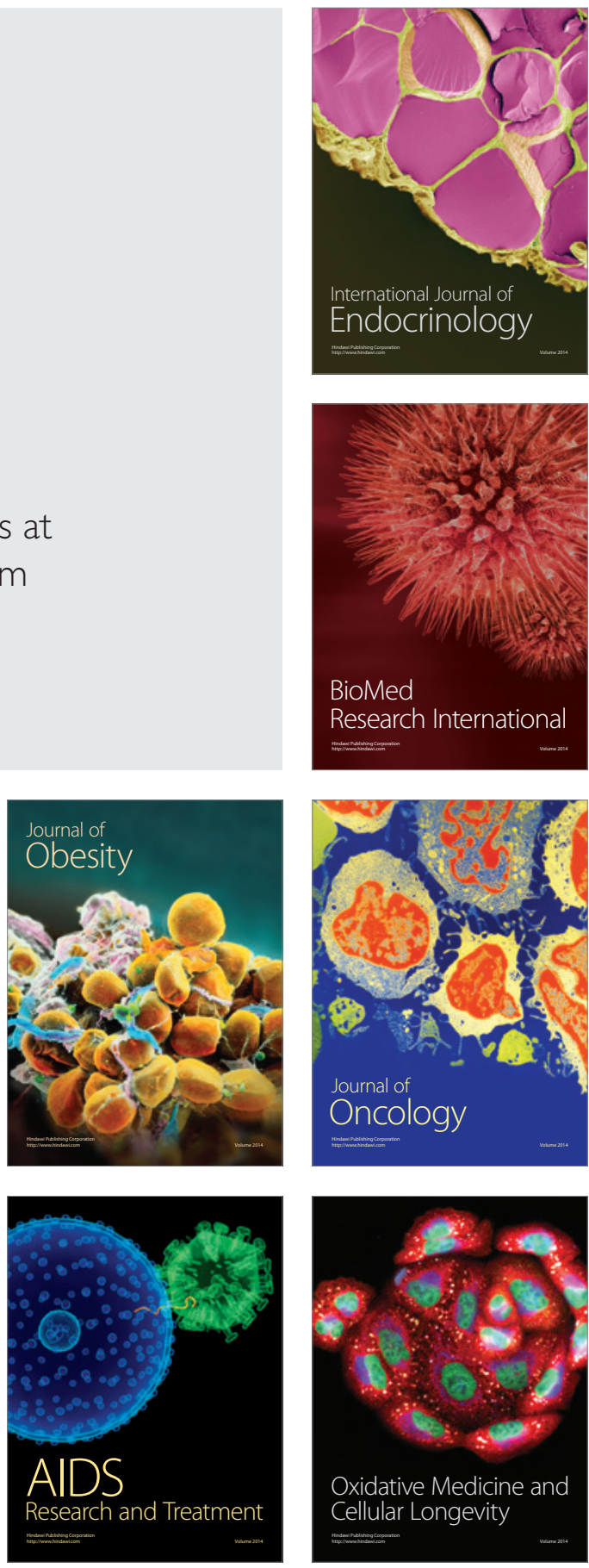